\title{
POR UMA EDUCAÇÃO LIBERTADORA E UMA DIDÁTICA FUNDAMENTAL COM PESSOAS EM PRIVAÇÃO DE LIBERDADE ${ }^{1}$
}

\author{
Jilvania Lima dos Santos Bazzo ${ }^{2}$ \\ Universidade Federal de Santa Catarina \\ http://orcid.org/0000-0002-8000-9130 \\ Rui Dias Florêncio ${ }^{3}$ \\ Casa da Criança do Morro da Penitenciária (Florianópolis - SC) \\ http://orcid.org/0000-0003-1075-8360
}

\begin{abstract}
RESUMO:
Neste artigo, objetiva-se refletir sobre a educação libertadora no contexto da Socioeducação ou da Educação em Prisões, fundamentados nas dimensões político-social e humana de uma educação libertadora, com vistas à superação da prática da educação bancária e da violência simbólica, com pessoas em privação de liberdade. Pretende-se aprofundar a discussão acerca dos aspectos pedagógicos e da atuação docente na educação com pessoas em privação de liberdade por meio de uma breve articulação conceitual entre as perspectivas de Paulo Freire (2018), Pierre Bourdieu e Jean-Claude Passeron (2013) acerca da cultura escolar. Como é possível praticar uma educação libertadora, com vistas à superação da educação bancária e da prática da violência simbólica, com pessoas em privação de liberdade? Para responder tal problemática, recortamos uma abordagem metodológica fundamentados na perspectiva multidimensional da Didática apresentada por Candau (2013) e empreendemos uma pesquisa bibliográfica a fim de pensar a educação com pessoas em privação de liberdade no âmbito político-social e humano, escolhendo como autores de referência as contribuições de Freire (2018) e Bourdieu e Passeron (2013). Na sequência, partimos para as contribuições de autores que são referência no âmbito da dimensão humana do processo de ensino e aprendizagem, tais como Neill (1995) e Rogers (2004). Ainda que parciais, os resultados apontam que a prática da ação dialógica com pessoas em privação de liberdade é uma proposta que permite superar a educação bancária e a violência simbólica, contribuindo para a emancipação social destas pessoas.
\end{abstract}

Palavras-chave: Educação. Didática. Violência simbólica. Educação bancária. Educação libertadora. Ação dialógica. Privação de liberdade.

\footnotetext{
$1 \quad$ Este artigo faz parte de uma pesquisa intitulada, provisoriamente, "Sonho ou utopia? Em busca de uma educação libertadora" que vem sendo desenvolvida no âmbito do Doutorado em Educação no Programa de Pós-Graduação em Educação (PPGE), da Universidade Federal de Santa Catarina (UFSC), e está vinculada ao Grupo de Estudos e Pesquisas em Didática e suas Multidimensões - GEPDiM/UFSC. http://dgp.cnpq.br/dgp/espelhogrupo/520118.

2 Doutora em Educação (UFSC). Professora do Departamento de Metodologia de Ensino (MEN) e do Programa de Pós-Graduação em Educação (UFSC). Líder do Grupo de Estudos e Pesquisas em Didática e suas Multidimensões - GEPDIM. E-mail: jilvania.bazzo@ufsc.br

3 Mestre em Reabilitação Psicomotora (Faculdade de Motricidade Humana da Universidade de Lisboa). Psicomotricista na Casa da Criança do Morro da Penitenciária (Florianópolis - SC) e na Associação Caminhos para a Vida (Florianópolis - SC). E-mail: ruidiasflorencio@gmail.com
} 


\section{ABSTRACT:}

\section{FOR A LIBERATING EDUCATION AND A FUNDAMENTAL DIDACTIC WITH PEOPLE IN DEPRIVATION OF LIBERTY}

This article aims to reflect on liberating education in the context of Socioeducation or Education in Prisons, based on the political-social and human dimensions of liberating education, with a view to overcoming the practice of banking education and symbolic violence, with people in deprivation of liberty. It is intended to deepen the discussion about the pedagogical aspects and the teaching performance in education with people in deprivation of liberty through a brief conceptual articulation between the perspectives of Paulo Freire (2018), Pierre Bourdieu and Jean-Claude Passeron (2013) about school culture. How is it possible to practice a liberating education, with a view to overcoming banking education and the practice of symbolic violence, with people in deprivation of liberty? To answer this problem, we cut out a methodological approach based on the multidimensional perspective of Didactics presented by Candau (2013) and we undertake a bibliographic research in order to think about education with people in deprivation of liberty in the political-social and human scope, choosing as authors of reference the contributions of Freire (2018) and Bourdieu and Passeron (2013). In the sequence, we start with the contributions of authors who are reference in the scope of the human dimension of the teaching and learning process, such as Neill (1995) and Rogers (2004). Although partial, the results show that the practice of dialogical action with people in deprivation of liberty is a proposal that allows to overcome banking education and symbolic violence, contributing to the social emancipation of these people.

Keywords: Education. Didactic. Symbolic violence. Banking education. Liberating education. Dialogic action. Deprivation of liberty.

\section{RESUMEN:}

\section{POR UNA EDUCACIÓN LIBERADORA Y UNA DIDÁCTICA FUNDA- MENTAL CON PERSONAS EN PRIVACIÓN DE LIBERTAD}

Este artículo tiene como objetivo reflexionar sobre la educación liberadora en el contexto de la Socioeducación o Educación en Prisiones, a partir de las dimensiones político-sociales y humanas de la educación liberadora, con miras a superar la práctica de la educación bancaria y la violencia simbólica, con personas en privación de libertad. Se pretende profundizar la discusión sobre los aspectos pedagógicos y el desempeño docente en educación con personas en privación de libertad a través de una breve articulación conceptual entre las perspectivas de Paulo Freire (2018), Pierre Bourdieu y Jean-Claude Passeron (2013) sobre la cultura escolar ¿Cómo es posible practicar una educación liberadora, con miras a superar la educación bancaria y la práctica de la violencia simbólica, con personas privadas de libertad? Para dar respuesta a esta problemática, recortamos un abordaje metodológico basado en la perspectiva multidimensional de la Didáctica presentada por Candau (2013) y realizamos una investigación bibliográfica con el fin de pensar la educación con personas en privación de libertad en el ámbito político-social y humano, eligiendo como autores de referencia los aportes de Freire (2018) y Bourdieu y Passeron (2013). En la secuencia, partimos de las aportaciones de autores referentes en el ámbito de la dimensión humana del proceso de enseñanza y aprendizaje, como Neill (1995) y Rogers (2004). Aunque parcial, los resultados muestran que la práctica de la acción dialógica con personas en privación de libertad es una propuesta que permite superar la educación bancaria y la violencia simbólica, contribuyendo a la emancipación social de estas personas.

Palabras clave: Educación, Didáctica, Violencia simbólica, Educación bancaria, Educación liberadora, Acción dialógica, Privación de libertad. 


\section{Introdução}

Educação... Quando o senhor chega e diz "educação", vem do seu mundo. O mesmo, um outro. Quando eu sou quem fala vem dum outro lugar, de um outro mundo. Vem dum fundo de oco que é o luar da vida dum pobre, como tem gente que diz. Comparação, no seu, essa palavra vem junto com quê? Com escola, não vem? Com aquele professor fino, de roupa boa, estudado, livro novo, bom, caderno, caneta, tudo muito separado, cada coisa do seu jeito, como deve ser... Do seu mundo vem estudo de escola que muda gente em doutor. É fato? Penso que é, mas eu penso de longe, porque eu nunca vi isso aqui. - fala de Antônio Cícero de Souza, o Ciço, um camponês de Minas Gerais com quem Carlos Brandão (1980 apud FREIRE, 1997, p. 36) teve um diálogo sobre educação.

A modernidade e o ensino escolar se constituem como um contexto marcado pela falta de sensibilidade para encontrar a "boniteza" que o professor e antropólogo Carlos Brandão (1980 apud FREIRE, 1997) encontrou e transcreveu da fala de Antônio Cícero de Souza ${ }^{4}$."Boniteza" essa que, segundo Freire (1997), deve ter a atenção especial de todos e todas as educadoras e educadores, se comprometendo com a pesquisa epistemológica do "saber de experiência feito" das classes populares, antes ou concomitantemente com a pesquisa sobre as práticas docentes.

$\mathrm{Na}$ ótica de Freire (1997), este saber sobre o qual a etnociência se tem ocupado e que se debruça acerca do saber da cultura dos grupos populares - sobre como sabem e como sistematizam o seu saber - deve ser o ponto de partida para a prática pedagógica democrática, pois é a partir do conhecimento dos educandos e das educandas que os educadores ou educadoras haverão de iniciar o seu diálogo pedagógico.

Freire (1997) pondera que a busca pela multiculturalidade não se institui na justaposição de culturas, nem no poder exacerbado de umas sobre as outras, mas na liberdade conquistada e no direito assegurado de cada cultura ter o respeito das outras, correndo o risco de ser diferente e sem medo de o ser. Só assim é possível que as diversas culturas cresçam juntas, sem a tensão permanente provocada pela soberania de uma sobre as outras. A multiculturalidade trata-se de uma escolha democrática de um caminho que jamais estará terminado e acabado, pois, necessariamente, se refaz a cada momento.

Freire (1997) entende que a tensão vivida deve ser a do inacabamento que se assume como razão de ser da própria cultura e de conflitos não antagônicos e não aquela anteriormente

$4 \quad$ Trata-se de parte da fala transcrita sobre educação de Antônio Cícero de Souza, o "Ciço", lavrador do sul de Minas Gerais, publicada originalmente no prefácio de um livro-coletânea sobre a educação popular, de que Paulo Freire fez parte, intitulado A questão política da educação popular, e organizado por Carlos Brandão em 1980. (BRANDÃO, 1980). 
causada pelo medo, pela desesperança ou pela injustiça. Portanto, Freire (1997) critica a forma como a escola ignora e apaga a cultura e o saber popular, impondo de forma autoritária e não democrática o ensino de um saber que, muitas vezes, está muito longe da realidade dos educandos e das educandas.

Com um pensamento similar, Bourdieu e Passeron (2013) explicam que o trabalho pedagógico escolar visa impor a legitimidade da cultura dominante, camuflando o poder arbitrário que é exercido sobre os membros dos grupos ou classes dominadas. Os autores afirmam que o fato da cultura das classes dominantes ser aquela que é valorizada pela escola, ao contrário do saber das classes populares, que é desvalorizado, faz com que a cultura dominante seja considerada como a única cultura autêntica, ou seja, como cultura universal.

Além disso, um dos efeitos menos percebidos da escolaridade obrigatória é o reconhecimento das classes dominadas do saber e do saber-fazer legítimos na sua sociedade, por exemplo, em matéria de direito, de medicina, de técnica, de entretenimento ou de arte, e a desvalorização do saber e do saber-fazer que elas efetivamente dominam, por exemplo, o direito consuetudinário, a medicina tradicional, as técnicas artesanais, a língua ou a arte popular (BOURDIEU; PASSERON, 2013).

Na visão de Bourdieu e Passeron (2013), o trabalho pedagógico tende a condenar os profetas ou criadores e a estimular uma homogeneização da cultura em detrimento da criação individual, pois a finalidade da programação escolar é a reprodução cultural e social. Nesta ótica, a função do ensino é a de legitimar a cultura dominante e valorizar socialmente aqueles que a possuem, tendo como finalidade a conservação social e a perpetuação das relações de classe e as estruturas de poder. Estes autores afirmam que todo o sistema de ensino institucionalizado tem as suas caraterísticas específicas de estrutura e funcionamento voltadas para a sua função de reprodução de um arbitrário cultural do qual ele não é o produtor, que designam de reprodução cultural. Desse modo, o sistema escolar contribui para a reprodução das relações entre os grupos ou classes, num processo que Bourdieu e Passeron (2013) designam de reprodução social.

Bourdieu e Passeron (2014) demonstram como o sistema escolar, que é revestido por uma aparência de neutralidade e democratização, continua a reproduzir as desigualdades sociais, camufladas pela ilusão da meritocracia. No seu trabalho sobre o sistema de ensino como reprodutor social fica clara a ligação estreita entre classe e sucesso escolar, mostrando como os mecanismos de seleção escolar se tornam dispositivos legitimadores da máquina de reprodução, e excluem aqueles que não são os legítimos "herdeiros" do sistema, pois estão mais longe da cultura dominante que ele privilegia 
Segundo Bourdieu e Passeron (2013, p. 30), “as contestações mais radicais de um poder pedagógico se inspiram na utopia autodestrutiva de uma pedagogia sem arbitrário". Na perspectiva destes autores, essas utopias visam a garantir o monopólio da imposição legítima, mascarando a verdade objetiva de toda ação pedagógica. Para tanto, elas mascaram a "violência simbólica" que reside em toda e qualquer ação pedagógica, pois, “toda ação pedagógica é objetivamente uma violência simbólica enquanto imposição, por um poder arbitrário, de um arbitrário cultural.” (BOURDIEU; PASSERON, 2013, p.26). Neste sentido, a ideia de uma ação pedagógica culturalmente livre, que não possua arbitrário, nem no que impõe e nem na maneira de fazê-la, consiste numa espécie de mascarar a verdade objetiva da ação pedagógica.

As abordagens de Bourdieu e Passeron (2013) e Freire (2018) nos provocam a pensar a seguinte questão: como é possível praticar uma educação libertadora, com vistas à superação da educação bancária e da prática da violência simbólica, com pessoas em privação de liberdade? ${ }^{5}$ Para responder tal problemática, recortamos uma abordagem metodológica fundamentados na perspectiva multidimensional da Didática apresentada por Candau (2013) e empreendemos uma pesquisa bibliográfica a fim de pensar a educação com pessoas em privação de liberdade no âmbito político-social e humano, escolhendo como autores de referência as contribuições de Freire (2018) e Bourdieu e Passeron (2013). Na sequência, partimos para as contribuições de autores que são referência no âmbito da dimensão humana do processo de ensino e aprendizagem, tais como Neill (1995) e Rogers (2004), pois apesar de partirem de uma visão liberal de educação podem nos ajudar a profundar essas dimensões da "Didática Fundamental" (CANDAU, 2013). Por fim, reunimos as contribuições apresentadas numa reflexão sobre a prática da educação libertadora com pessoas em privação de liberdade.

Este trabalho tem como objetivo refletir sobre a educação libertadora no contexto da Socioeducação ou da Educação em Prisões, fundamentado nas dimensões político-social e humana de uma educação libertadora, com vistas à superação da prática da educação bancária e da violência simbólica, com pessoas em privação de liberdade. Consideramos que este artigo pode ajudar a responder à necessidade apontada nos estudos de se aprofundar a discussão acerca dos aspectos didático-pedagógicos e da atuação docente na educação com pessoas em privação de liberdade (FONSECA, 2013; ONOFRE; 2015; DUARTE; PEREIRA, 2017; PESSOA; ALBERTO; LEITE, DOS SANTOS; ROCHA, 2019; ONOFRE, FERNANDES; GODINHO, 2019). Importa destacar ainda que a reflexão apresentada poderá também servir de fonte para estudos

5 Conforme consta na primeira nota de rodapé, esta questão de pesquisa faz parte de um trabalho de investigação mais amplo, cujo título ainda provisório é: "Sonho ou utopia? Em busca de uma educação libertadora". 
e investigações em torno dos conceitos teóricos e metodológicos que envolvem os processos educativos no âmbito da Socioeducação, ou da Educação em Prisões.

\section{Violência simbólica e educação libertadora: da dimensão político- social do ato de ensinar}

A perspectiva de Bourdieu e Passeron (2013) de que qualquer ação pedagógica consiste numa violência simbólica, na medida em que se trata de uma imposição de um arbitrário cultural, parece estar alinhada com uma ideia de cultura ${ }^{6}$ como algo estanque, e não como algo dinâmico e vivo, que é constantemente recriado. Trata-se de uma concepção que entende as pessoas envolvidas nos processos educativos como meras reprodutoras culturais e não leva em conta a sua agência como produtoras de cultura, notadamente os educandos e educandas. Isto é algo particularmente característico da visão adultocêntrica do pensamento ocidental, que não enxerga os educandos e educandas como sujeitos epistêmicos e produtores de cultura, mas como um "vir a ser" (TASSINARI, 2007). Portanto, os educandos e educandas são vistos como pessoas que precisam ser educadas para poderem se tornar sujeitos, ou seja, são vistos como objetos passivos da educação.

Essa análise está de acordo com Bicalho e Paula (2009) que apontam que Bourdieu e Passeron (2013) na sua concepção de violência simbólica não consideram o sujeito como um agente da relação, mas como alguém que apenas se resigna. Na compreensão de Bicalho e Paula (2009), eles apresentam uma visão que não abre a possibilidade de uma mudança concreta no mundo social, e que vê a ordem como algo inquestionável na reprodução da sociedade. No mesmo sentido, Toscan (2011) aponta que, na sua teoria da violência simbólica, Bourdieu e Passeron (2013) negam a autonomia e a consciência dos sujeitos nas relações pedagógicas que são estabelecidas.

Toscan (2011) aproxima a perspectiva da violência simbólica de Bourdieu e Passeron (2013) com a prática da educação bancária descrita por Freire (2018) como aquela baseada em programas educacionais engessados, que visam “depositar" conteúdos de uma forma impositiva. Ao fazer a sua crítica à educação bancária, Freire (2018) apresenta uma proposta educacional alternativa e possível, baseada na sua teoria de ação dialógica, que nos permite refletir sobre como superar a reprodução da educação bancária e da ação pedagógica como violência simbólica.

6 Salientamos que a concepção de cultura como algo estanque na perspectiva de Bourdieu e Passeron (2013) se refere à sua utilização neste livro na sua definição de ação pedagógica. Sabemos que corremos o risco de fazer uma referência ao conceito numa perspectiva diferente daquela que o próprio Bourdieu mobiliza em outros momentos da sua obra. Reforçamos, porém, que nos referimos aqui especificamente à sua utilização no âmbito da conceptualização da ação pedagógica e que está devidamente datada. 
Na sua teoria da ação dialógica, Freire (2018) defende que o adulto "socializador" não deve ser o único a ser visto como agente, recusando a ideia da passividade da recepção dos valores, princípios e atributos sociais. Para tal, Freire (2018) substitui essa ideia pela noção de construção de significados e sentidos na interação e interlocução. Além disso, tal como nos aponta Glass (2013), a educação libertadora proposta por Freire visa, principalmente, estimular a criticidade e o poder dos aprendizes de intencionalmente transformarem a si e ao seu mundo.

Conforme as conclusões apresentadas por Glass (2013), a teoria freiriana de prática da educação libertadora assenta na perspectiva ontológica de que produzimos história e cultura ao mesmo tempo em que história e cultura nos produzem. Nessa perspectiva é possível pensar uma pedagogia que auxilia as pessoas a despertarem para a força que cada um tem dentro de si, e que reside na liberdade e na capacidade que temos de fazer algo novo, que transforma o mundo material e transcende os sentidos e as práticas histórico-culturais que recebemos. Deste modo, Freire (2018) afirma a nossa existência ontológica de coprodutores do mundo histórico e cultural onde vivemos.

Na mesma linha de Freire (2018), Oliveira (1999) afirma que a coeducação só pode acontecer na medida em que as pessoas se reconhecem como seres inacabados, o que não pode ser visto como uma caraterística de determinadas fases da vida, mas um atributo humano. Lapassade (1975 apud OLIVEIRA, 1999) afirma que esse inacabamento é o que possibilita a própria cultura, pois é o que nos permite estarmos constantemente nos recriando, qualquer que seja a idade. O outro é aquele que testemunha o nosso inacabamento e nos ajuda a nos humanizarmos, pelo que a recriação de si só pode ocorrer no encontro com esse outro. Nesta forma de ver o mundo, viver é o processo de nos tornarmos o que somos em potencialidade, tal como é proposto por Fromm (1968 apud OLIVEIRA, 1999).

Por outro lado, a vertente teórica de Bourdieu e Passeron (2013) sobre a temática da violência simbólica parece estar baseada numa visão de poder $^{7}$ no campo educacional como algo exclusivamente centralizado na figura e no papel de quem educa, pois consideram que a ação pedagógica é uma imposição de um arbitrário cultural por um poder arbitrário. Pelo contrário, a educação libertadora parece estar relacionada com uma visão de poder próxima com aquela descrita em Foucault (2008), ou seja, o poder pertence àqueles que decidem, que tomam para si a tarefa de escolher, tomar decisões.

Numa visão foucaultiana, poderíamos dizer que o poder, ao contrário das perspectivas convencionais que afirmam a sua centralidade e posse, é exercido em múltiplas direções, como se

$7 \quad$ Conforme já registramos na nota de rodapé anterior, neste texto o conceito de cultura está circunscrito na obra publicada por Bourdien e Passeron em 2013 e se refere especificamente à sua mobilização no âmbito da conceptualização da ação pedagógica. (BOURDIEU; PASSERON, 2013). 
fosse uma rede que se constitui por toda a sociedade. Foucault (2008) concebe o poder exercido a partir de manobras, técnicas ou disposições que não deixam de serem resistidas, respondidas, absorvidas, aceitas ou transformadas. As relações têm inerentes a si os seus jogos de poder, que consistem em enfrentamentos constantes e perpétuos, e aos quais está inerente, também, a liberdade e o potencial de revolta.

Louro (2011) salienta que as concepções foucaultianas sobre o poder trouxeram ainda outro contraponto às ideias tradicionais, que consiste em percebê-lo não apenas como coercitivo e negativo, mas como produtivo e positivo. Assim, o poder passa a ser visto não apenas como aquele que nega, impede, ou coíbe, mas, também, como aquele que produz, faz ou incita.

Na ressonância desse horizonte epistemológico, Freire (2018) também nos aponta que a liberdade é uma conquista e não uma doação. Portanto, a liberdade à qual se refere na sua pedagogia libertadora não é um conceito abstrato, um ponto ideal fora das pessoas ao qual elas poderiam se alienar. Freire (2018) concebe a liberdade como um movimento de busca permanente, pois ninguém tem liberdade para ser livre e, por isso mesmo, precisamos estar constantemente engajados na luta e nesse movimento de conquista. Ser livre significa correr riscos, dar um passo além na busca do ser mais, sabendo que a busca não se faz sozinho, mas com o outro, pois como diria Freire (2018, p. 29) “ninguém liberta ninguém, ninguém se liberta sozinho, os homens se libertam em comunhão, mediatizados pelo mundo".

A liberdade, por assim dizer, trata-se do próprio processo de busca, que leva à comunhão criadora e que permite aos indivíduos serem autenticamente, afirmando-se como atores da própria história. Ela exige a disponibilidade para o autoconhecimento e a coragem de decidir ser, existir nos seus autênticos desejos, afirmando o seu poder de criar e de transformar o mundo com os outros, em comunhão, desde que não implique concretamente desejo de morte. Se assim o for, o mais prudente é o afastamento protetor e curador. Não existem pessoas livres, mas pessoas em processo de libertação, que acontece a partir do momento em que nos engajamos no estabelecimento de relações autênticas com o outro e conosco próprios. Portanto, é somente na comunicação, interação e interlocução, que tem sentido a vida humana, pois o pensar de uma pessoa somente ganha autenticidade no pensar dos outros, mediatizados pelo mundo e em intercomunicação. (FREIRE, 2018).

Por esta razão, o diálogo é visto como uma exigência existencial, tratando-se do encontro entre pessoas que pronunciam o mundo, sendo essa a base de construção do conhecimento, enquanto ato de criação. Por isso, Freire (2018) acredita que não há diálogo se não houver um profundo amor ao mundo e aos outros. $\mathrm{O}$ ato de criação é fundado pelo amor que torna possível 
o diálogo, realizado em relação horizontal, cuja base é a confiança. Através dessa verdadeira comunhão é possível gerar a verdadeira colaboração que torna possível a ação libertadora.

Na mesma linha do pensamento pedagógico freiriano, Oliveira (1999) utiliza o termo “coeducação" para definir o processo através do qual se podem alcançar relações igualitárias, no qual ocorre uma modificação recíproca dos sujeitos, que surge quando ambos convergem na busca de relações onde se aceitam as diferenças interindividuais. Aqui não cabe a distinção entre educador e educando, mas, sim, a definição de uma comunidade de indivíduos que juntos problematizam o mundo e buscam soluções coletivas para as questões percebidas.

Esta forma de educação implica, então, a superação da contradição educador e educandos, de tal modo que ambos sejam, simultaneamente, educadores e educandos, professor e estudantes. O método de ensino é visto como uma atitude de desejar ensinar e aprender. Freire (1997) enfatiza que o/a educando/a precisa se reconhecer como sujeito que é capaz de conhecer e que quer conhecer em relação com outro sujeito, que também se reconhece como capaz de conhecer, para que, assim, ambos consigam alcançar o objeto de conhecimento. Ensinar e aprender são, deste modo, vistos como o processo de conhecer, que implica re-conhecer-se a si mesmo.

Freire (1997) pondera que a grande importância política do ato de ensinar consiste em permitir que os educandos e educandas se assumam como sujeitos cognoscentes e, à medida em que vão imergindo nos significados e atribuindo sentidos, vão se tornando também significadores críticos. Nos círculos de cultura propostos pela sua pedagogia, ensina-se mutuamente, portanto, há aprendizagens em "reciprocidade de consciências" e em diálogo circular, intersubjetivando-se em cooperação, colaboração e afetividade. Assim, as pessoas vão assumindo, criticamente, o dinamismo de sua subjetividade criadora.

\section{Educação libertadora e violência simbólica: da dimensão humana do ato de ensinar}

Somando-se à teoria crítica freiriana, compreendemos que Neill (1995) e Rogers (2004), que são referências das pedagogias não-diretivas, podem colaborar no aprofundamento das práticas libertadoras, pois a partir das suas ideias podemos concluir que uma pedagogia que não se utilize da violência simbólica é aquela em que o educador ou a educadora aceita incondicionalmente o educando ou a educanda como ele ou ela é. Desse modo, é possível não condicionar a pessoa a ser como nós gostaríamos que ela fosse, ou da maneira como nós próprios, fôssemos e não conseguimos ser. 
Kohan (2007) afirma que quando falamos em formar cidadãos solidários, tolerantes, respeitosos e democráticos, estamos a afirmar como nós gostaríamos de ser e não somos. Portanto, quando o educando ou a educanda é aceita pelo educador ou educadora como ele(ela) é, pode, a partir dessa aceitação, aceitar-se a si mesmo(a) e permitir-se ser autêntico(a). Ou seja, como poderia um educador ou educadora ensinar um educando ou educanda a aceitar-se a si mesmo(a) e a ser autêntico(a), se ele(a) não se aceita? A mediação do processo educativo é uma "atividade de parceria, disposição para estar com o outro; é uma atitude de coração e coragem, somente homens e mulheres inteligentes, sensíveis e humanos são capazes de desenvolvê-la" (BAZZO, 2020, p. 280).

Podemos, com o debate, considerar que o exercício de uma educação libertadora consiste no envolvimento de um processo de crescimento e amadurecimento estabelecido entre pessoas. Tal processo exige o desenvolvimento conjunto de capacidades para estabelecer relações autênticas, se engajando num percurso de transformação mútua. De acordo com Rogers (2004), o estabelecimento de relações autênticas depende da capacidade de não julgar a si próprio nem ao outro, desenvolvendo a aceitação empática e o acolhimento amoroso.

A empatia consiste na capacidade de se colocar no lugar do outro e é a base para uma relação sem condicionamentos, na qual se permite que esse outro seja o que verdadeiramente é. As competências da aceitação incondicional do outro, autenticidade e empatia, que foram definidas por Rogers (2004) apresentam-se como fundamentais na ação pedagógica e terapêutica, e são a base para a criação de uma relação libertadora, da qual a confiança vai se tornando o seu principal suporte.

Neill (1995) considera que a libertação do outro consiste na sua aprovação, pois é apenas quando se sente aprovado na sua autenticidade, que se sente livre para ser o que é, tornando-se, assim, um ser social. O autor afirma que o amor cura, ou seja, a aprovação e a liberdade que se oferecem ao outro de ser fiel a si próprio. A aceitação do outro como ele é permite que ele aceite, de forma livre e sem receio, os sentimentos positivos que os outros nutrem em relação a si.

Isso faz com que a pessoa não apenas aprenda a se aceitar, como comece a gostar de si própria, o que não se trata de ser arrogante, mas de se sentir bem na sua própria pele. Desse modo, a pessoa desenvolve uma alegria de viver que é espontânea e livre, contagiando os que vivem ao seu redor e transparecendo um sentimento de plenitude e autorealização. (ROGERS, 2004).

Este processo de aceitação é fundamental para o desenvolvimento da pessoa, seja qual for a fase da vida em que se encontre. Em relação à pessoa em situação de privação de liberdade, é importante escutar a sua criança interna, saber sobre suas necessidades e o que ela precisa. $\mathrm{O}$ 
trabalho educativo haverá de iniciar com esses fundamentos: a pessoa é a mais importante, sua história de vida.

Como já vimos, o processo de libertação avança se o educando ou a educanda se sente aprovado(a) na sua autenticidade. Porém, o adulto educador ou educadora está, muitas vezes, mergulhado(a) nas suas próprias fragilidades, pois as desaprovações que sofreu ao longo da sua vida fazem com que não consiga aprovar a si próprio. Consequentemente, não consegue aprovar o outro, encontrando-se demasiadamente autocentrado e sem conseguir reconhecê-lo e valorizá-lo.

Envolver-se no processo de aceitar o outro implica envolver-se no processo de aceitar a si mesmo(a), para assim poder entrar em relações de reciprocidade, que Buber (2009) define como a relação "Eu-Tu". Portanto, para o educador ou a educadora auxiliar o educando ou a educanda no seu processo de libertação ele ou ela deve também estar envolvido no seu próprio processo de libertação.

O amor, que significa confiar, respeitar e aceitar o eu do outro, é a ferramenta educacional e terapêutica mais poderosa. Ele é a cura. Ele consiste em permitir a liberdade e aprovação para ser o que se é. O único condicionamento que as nossas emoções deveriam receber deveria ser o condicionamento do amor. Neste sentido, podemos encontrar uma ponte entre Neill (1995), Rogers (2004), Buber (2009), Freire (1997) e João dos Santos (n/d apud BRANCO, 2000), criador da "Pedagogia Terapêutica", para quem a arte de educar, de curar e de amar são na sua base idênticas, e consistem, essencialmente, em colocar o seu próprio funcionamento neutral ao serviço do funcionamento dos outros.

Isto não significa que uma educação libertadora não implica a integração de limites, tendo em vista que a liberdade consiste em fazermos o que quisermos, desde que não se interfira com a liberdade alheia. Portanto, não tem problema dar limites, desde que isso não seja feito - de uma posição moralista, ou seja, julgando e culpabilizando as ações do outro. O importante é saber como dar limite sem culpabilizar. (NEILL, 1995).

Freire (2018) afirma que não exercer autoritarismo não significa ter uma posição liberalista, que levaria os outros a licenciosidades. A teoria dialógica freiriana nega o autoritarismo da mesma forma que nega a licenciosidade, afirmando, assim, a autoridade e a liberdade. Da mesma maneira, Neill (1995) assegura que numa educação disciplinada o educando(a) não tem direitos, enquanto que numa educação licenciosa ele(a) tem todos os direitos.

Freire $(2018$, p.103) afirma que "se não há liberdade sem autoridade, não há também esta sem aquela", portanto, o que está na base da autoridade autêntica é a liberdade que em certo momento se faz autoridade. Não se tratam de realidades antagônicas, nem separáveis 
uma da outra, pois toda hipertrofia de uma provoca a atrofia da outra. A verdadeira pedagogia, destaca Freire (2018), é aquela em que dois seres fazem juntos o aprendizado da autoridade e da liberdade verdadeiras, que ambos, como um só corpo, buscam instaurar ao transformarem a realidade que os mediatiza.

\section{A busca do Ser-Mais, ou da aprendizagem da relação EU-TU}

Segundo Freire (2018), os seres humanos vivem permanentemente uma relação dialética entre os condicionamentos e a sua liberdade. As barreiras que os seres humanos encontram e que restringem as suas liberdades, Freire (2018) chamou de "situações-limite". Para enfrentar essas "situações-limite", os seres humanos devem tomar distância, objetivando aquilo que os limita, que ele nomeou como "percebido-destacado". No momento em que os seres humanos tomam consciência dos seus limites e percebem esses obstáculos à sua libertação, iniciam a sua ação libertadora, realizando aquilo que Álvaro Vieira Pinto (n/d apud FREIRE, 2018) designa de "atos-limites", que são aqueles que se dirigem à superação dos limites da realidade.

Freire (2018) ressalta que, no momento em que a percepção crítica se inaugura, se gera um clima de esperança e confiança que leva os seres humanos a se empenharem na superação dessas situações que os limitam. Essa superação, envolta na crença, no sonho possível e na utopia que virão, faz os seres humanos partirem em busca do que ele designou de "inédito-viável”, que é algo não conhecido ou vivido, e que ao se tornar realidade permite com que os seres humanos concretizem a sua vocação de Ser-Mais.

Na visão de Freire (2018), esta superação só pode acontecer na ação sobre a realidade concreta, na medida em que a partir do momento em que forem superadas essas situações, com a transformação da realidade, novas situações surgirão, solicitando novos "atos-limite". O constante enfrentamento com a realidade vai delineando a dimensão histórica do ser humano, que vai sendo operada de transformação em transformação, num movimento de permanente devir.

Fica evidente que, na teoria dialógica freiriana, não pode haver um sujeito que domina pela conquista e um objeto dominado. Ao contrário, existem sujeitos que se encontram para a pronúncia do mundo e para a sua transformação. Na teoria da ação antidialógica, que Freire (2018) procura combater, a conquista implica a transformação do outro em quase "coisa", pois o eu dominador transforma o tu dominado num mero "isto". Em contraposição, o eu dialógico sabe que é exatamente o tu que o constitui e, ao ser constituído por um tu, esse tu se constitui, também, como um eu, pois enxerga no seu eu um tu. "Desta forma, o eu e o tu passam a ser, na dialética destas relações constitutivas, dois tu que se fazem dois eu." (FREIRE, 2018, p. 96). 
Resumindo, Freire (1997) não coloca o centro da sua perspectiva educativa nem no educando, nem no educador, nem no conteúdo, nem no método, mas nas relações humanas atravessadas pelos seus vários componentes. Nesta linha de pensamento, ele se aproxima das ideias de Buber (2009), cujo existencialismo se baseia numa fenomenologia da relação, mostrando que o amor não é algo possuído pelo eu como se fosse um sentimento, mas como algo que acontece entre dois seres humanos, situando-se além do eu e aquém do tu, ou seja, na esfera entre os dois. O encontro com o tu é algo que exige que o eu se coloque disponível através de um ato do seu ser, que é o ato de voltar-se ao outro, sendo, portanto, o seu ato essencial/vigoroso. A realização do eu acontece na relação com o tu, na medida em que "toda verdadeira vida é encontro" (BUBER, 2009, p. 49).

Na compreensão de Buber (2009), a relação Eu-Tu é a origem primordial do ser humano, na medida em que cada um se torna eu na relação com o tu. Portanto, a relação Eu-Tu dá-se ao nível do ato puro, da ação sem arbitrariedade. Nessa abordagem, somente quando as pessoas entram, verdadeiramente, em relação é que se tornam livres e, portanto, criadoras. Deste modo, o ser humano é tanto mais uma pessoa, quanto mais intenso é o seu eu. A afirmação do seu eu, ou seja, o que a pessoa quer dizer quando se diz, decide o seu lugar e para onde leva o seu caminho.

\section{A educação libertadora com pessoas em privação de liberdade}

A partir das perspectivas teóricas já apresentadas, podemos afirmar que Bourdieu e Passeron (2013) e Freire (2018) convergem na crítica que fazem à deslegitimação do saber e da cultura popular operada pelo ensino escolar, que os primeiros descrevem através do conceito de violência simbólica e o segundo do conceito de educação bancária. A contribuição desses autores, que abarca principalmente a dimensão político-social e humana do processo de ensino e aprendizagem, juntamentamente com a colaboração de outros autores para aprofundar a discussão desse processo, tais como Neil (1995) e Rogers (2004), permite-nos refletir sobre como realizar uma educação libertadora, indo além da prática da educação bancária e da violência simbólica, com pessoas em privação de liberdade.

Glass (2013) destaca que o atual contexto global de políticas neoliberais produzem práticas educacionais baseadas em testagem, classificação e seleção, e vêm se reproduzindo no modelo de educação bancária criticado por Freire (2018). Neste cenário, as pessoas que participam desses processos educacionais continuam sendo envolvidas num sistema de reprodução da violência simbólica, tal como foi descrito por Bourdieu e Passeron (2018). 
A esse cenário se acrescenta o fato de que o modelo educativo que se coloca em prática no contexto de privação de liberdade é similar ao do ensino regular, mesmo se tratando de uma realidade tipicamente não formal, o que parece dificultar um trabalho pedagógico que leve em conta a realidade objetiva e concreta dos educandos e educandas. (FONSECA, 2013; DUARTE; PEREIRA, 2017).

Além disso, apesar de haver um reconhecimento de que a educação de jovens e adultos deve ser diferenciada, trazendo como missão a valorização do saber popular e o desenvolvimento de reflexões críticas sobre a sua realidade, existe, ainda, uma contradição entre o plano jurídico do direito à educação básica e a sua negação pelas políticas públicas. Mais ainda, mesmo que esses compromissos aparecem nesses documentos legais, falta uma reflexão mais aprofundada sobre como colocá-los em prática, além da consolidação das condições objetivas para tal (PESSOA; ALBERTO; LEITE, DOS SANTOS; ROCHA, 2019).

Dito isto, percebemos a importância de refletirmos sobre a teoria da ação dialógica freiriana como proposta que visa contrapor o presente cenário educacional marcado pela educação bancária, nomeadamente no contexto da educação de pessoas em privação de liberdade. Isto porque, a perspectiva freiriana nos permite refletir que é possível realizar uma educação libertadora, indo além dos processos educativos marcados pela violência simbólica. No âmbito da sociologia da educação, Bourdieu e Passeron (2013) nos apresentam um contributo importante para entendermos a reprodução cultural e social que acontece no processo de ensino e aprendizagem. Por outro lado, na sua proposta filosófica, social e política para a educação, Freire (2018) nos permite avançar numa perspectiva de superação dessa reprodução, por meio da ação dialógica que ocorre de modo horizontal, colaborativo e cooperativo. Portanto, a pedagogia libertadora consiste numa possível resposta à cultura de violência dos sistemas de ensino, atendendo à necessidade de se realizar uma educação baseada nos direitos humanos, que deve ser discutida e colocada em prática dentro das unidades prisionais (DUARTE; PEREIRA, 2017).

A proposta educacional de Freire (2018) apresenta um caminho de superação das relações pedagógicas centradas no educador ou educadora, ou nos conteúdos a serem "depositados" no educando ou educanda. Em contraposição, o autor defende que o centro dos processos educativos deve estar nas interações e interlocuções que se estabelecem no decorrer do próprio processo. Ou seja, naquilo que acontece a partir da ação dialógica. Portanto, para alcançar uma educação libertadora na qual não exista violência simbólica com pessoas em privação de liberdade é necessário colocar em prática os princípios da ação dialógica propostos por Freire (2018), alcançando relações pedagógicas que Buber (2009) define como relação Eu-Tu. 
Importa destacar que não significa que o conhecimento do conhecido terá prioridade sob o conhecimento do desconhecido. Em "Pedagogia da Esperança", Freire (1997) rebate as críticas à sua obra que o acusam de defender uma educação que se fique apenas pelo "saber de experiência feito" e que não permita o acesso ao conhecimento ciêntifico. Para tal, ele esclarece que na sua ótica é direito dos educandos e educandas conhecer o conhecido e conhecer o desconhecido. Portanto, na sua visão, tanto os conhecimentos universais quantos aqueles particulares e saberes singulares são potências criadoras e direito de todos e cada um de ter acesso e apreendê-los.

Os resultados desse estudo nos possibilitam refletir acerca das práticas pedagógicas libertadoras em contexto de privação de liberdade, na medida em que a ação dialógica não depende de condições externas aos sujeitos, mas da sua disposição para se envolverem num processo de libertação conjunta. Essa ação deve partir da disponibilidade dos educadores e educadoras para conhecerem a realidade particular dos educandos e educandas, valorizando o seu "saber de experiência feito" (ONOFRE, 2015; PESSOA; ALBERTO; LEITE, DOS SANTOS; ROCHA, 2019).

Ademais, tomando como ponto de partida os sujeitos e suas histórias de vida, podemos avançar para uma discussão no sentido da importância de ajudar as pessoas, envolvidas no processo de ensino e aprendizagem no contexto da Educação em Prisões ou Espaços Socioeducativos, a compreenderem as situações, os contextos e os limites do sistema político-econômico e social no qual estão inseridas e através do qual elas se fizeram homens e mulheres privadas de sua liberdade, contribuindo assim para a sua emancipação social. (ONOFRE, 2015; PESSOA; ALBERTO; LEITE, DOS SANTOS; ROCHA, 2019).

Para tal, é fundamental estimular os educadores e educadoras a conhecerem e a considerarem a realidade sociocultural e a cultura carcerária, como ponto de partida para as suas problematizações e intervenções pedagógicas. Por fim, destacamos a importância de aprofundar a reflexão sobre a necessidade da flexibilização curricular e da criação de propostas curriculares que respondam às necessidades específicas das pessoas em privação de liberdade. (ONOFRE; 2015; DUARTE; PEREIRA, 2017; PESSOA; ALBERTO; LEITE, DOS SANTOS; ROCHA, 2019; ONOFRE, FERNANDES; GODINHO, 2019).

\section{Considerações finais}

Neste artigo, procuramos aprofundar a teorização sobre os conceitos de educação libertadora e violência simbólica, trazendo as perspectivas de Freire (2018) e Bourdieu e Passeron (2013), e estabelecendo interlocuções entre eles e outros autores que colaboraram para pensarmos a educação de pessoas em privação de liberdade. A partir desssas contribuições, pudemos 
refletir sobre a possibilidade da prática de uma educação libertadora, destacando principalmente os aspectos teóricos e metodológicos da proposta que Freire (2018) nos apresenta para superar a educação bancária e a ação não dialógica.

Acreditamos que a exposição crítica apresentada, embora em construção - pelos motivos já explicitados nas notas de rodapé -, pode contribuir para o debate em torno dos processos educativos com pessoas em privação de liberdade. As pessoas que se encontram na condição de suspensão do direito de ir e vir não devem ser privadas do direito de se envolverem em processos educativos libertadores, considerando que a experiência de práticas dialógicas, conforme discutido anteriormente, pode ajudar no processo de compreensão do seu estado de ser cidadão de direito e de poder - isto porque aprenderão a olhar para o sistema de uma forma crítica, percebendo as suas estratégias mortíferas e também suas fragilidades.

Consideramos pertinente refletir sobre a importância de colocar a ação dialógica em prática no contexto de pessoas em privação de liberdade, ajudando-as a entenderem as situações-limite que enfrentam e os percebidos-destacados que as condicionam, para que todos juntos e cada um ou cada uma se engajem em processos coletivos de libertação que conduzam ao inédito-viável.

Finalmente, devemos ter em consideração que, tal como nos aponta Freire (2018), a liberdade trata-se do próprio processo de busca, e é algo que não pode ser doado nem tirado. Ela é uma conquista que cada pessoa deve fazer ao se engajar no movimento de se tornar autora da sua própria história, em comunhão, colaboração, cooperação e parceria na aventura de ser-sendo humano, verdadeiramente humano.

\section{Referências}

BAZZO, J. L. S. A didática na relação universidade escola - alguns apontamentos sobre a formação docente. In SOUZA, Alba; SOUTO-MAIOR, Lara; MARTINS FILHO, Lourival; SOLIGO, Marina (org.) Anos iniciais do ensino fundamental - Estágio Curricular Supervisionado e Formação Docente. $1^{\mathrm{a}}$ edição, Florianópolis, SC: Editora Insular, 2020, p. 271- 291.

BICALHO, Renata de Almeida; PAULA, Ana Paula Paes de. Violência Simbólica: uma leitura a partir da Teoria Crítica Frankfurtiana. II ENCONTRO DE GESTÃO DE PESSOAS E RELAÇÕES DE TRABALHO, Curitiba, 2009. Disponível em: < http://www.anpad. org.br/admin/pdf/EnGPR137.pdf>. Acesso em: 30 nov. 2020.

BOURDIEU, Pierre; PASSERON, Jean-Claude. A reprodução: elementos para uma teoria do sistema de ensino. Tradução de Reynaldo Bairão. 6a Edição. Petrópolis, Rio de Janeiro: Vozes, 2013 [1969].

. Os herdeiros: os estudantes e a cultura. Florianópolis: Editora da UFSC, 
BRANDÃO, Carlos Rodrigues (Org.). A questão política da educação popular. São Paulo: Brasiliense, 1980.

BRANCO, Maria. Vida, Pensamento e Obra de João dos Santos. Lisboa, Livros Horizonte, 2000 .

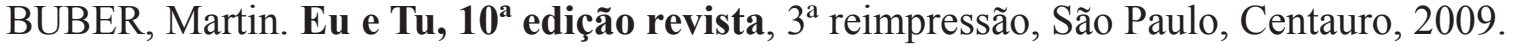

CANDAU, Vera Maria. A didática e a formação de educadores - da exaltação à negação: a busca da relevância. Em CANDAU, Vera Maria. (Org.). A didática em questão. Petrópolis, RJ: Vozes, 2013, p. 13-24.

DUARTE, Ana Maria Tavares; PEREIRA, Cleyton Feitosa. A educação de pessoas privadas de liberdade numa perspectiva inclusiva e ressocializadora: limites e contradições. Interritórios - Revista de Educação da Universidade Federal de Pernambuco, Caruaru, Brasil, V.3, N.5, 2017.

FONSECA, Débora. Escolarização de adolescentes em privação de liberdade: análise do tema em uma amostra de periódicos. Revista Eletrônica de Educação. São Carlos, SP: UFSCar, v. 7, no. 1, p. 13-31, mai. 2013. Disponível em http://www.reveduc.ufscar.br. Acesso em: 30 nov. 2020.

FOUCAULT, Micheal. Vigiar e Punir: nascimento da prisão. $35^{\text {a }}$ Edição. Petrópolis: Vozes, 2008.

FREIRE, Paulo. Pedagogy of the Opressed. New York, Bloomsbury Academic, 4th edition, 2018 [1968].

Pedagogia da Esperança: Um reencontro com a Pedagogia do Oprimido. Rio de Janeiro: Paz e Terra, 1997.

GLASS, Ronald David. Revisitando os fundamentos da educação para a libertação: o legado de Paulo Freire. Educ. Real. [online]. 2013, vol.38, n.3, pp.831-851. ISSN 2175-6236. https://doi.org/10.1590/S2175-62362013000300008.

KOHAN, Walter. Infância, estrangeiridade e ignorância. Belo Horizonte, MG: Autêntica, 2007.

LOURO, Guacira Lopes. Gênero, sexualidade e educação: uma perspectiva pós-estruturalista. 12.ed. Petrópolis, RJ: Vozes, 2011.

NEILL, Alexander. Summerhill School: A New View of Childhood. NewYork, 1st Ed. St. Martin's Griffin, 1995 [1960].

OLIVEIRA, Paulo. Vidas compartilhadas: cultura e co-educação de gerações na vida cotidiana. São Paulo: Hucitec: Fapesp, 1999.

ONOFRE, Elenice. Educação escolar para jovens e adultos em situação de privação de liberdade. Cad. CEDES [online]. 2015, vol.35, n.96, p.239-255. ISSN 1678-7110. http:// dx.doi.org/10.1590/CC0101-32622015723761. 
ONOFRE, Elenice; FERNANDES, Jarina; GODINHO, Ana Paula. A EJA em contextos de privação de liberdade: desafios e brechas à educação popular. Educação, 42(3), 465-474, 2019. https://doi.org/10.15448/1981-2582.2019.3.33770.

PESSOA, Manuella; ALBERTO, Maria de Fatima; LEITE, Fernanda; DOS SANTOS, Denise; ROCHA, Gabriela. Sujeitos da educação de jovens e adultos privados de Liberdade: um olhar na perspectiva histórico cultural. Em SANT'ANA, Nélson; TANUSS, Rebecka (org.). Educação de jovens e adultos privados de liberdade: ensaios interdisciplinares, João Pessoa: Editora do CCTA, 2019.

ROGERS, Carl. On Becaming a Person: A therapist's view of psychotherapy. London, Robinson Ed, 2004 [1961].

TASSINARI, Antonella. Concepções indígenas de infância no Brasil. In Revista Tellus, Ano 7, N. 13, Pp. 11-25. Campo Grande - MS, 2007.

TOSCAN, Loines Aparecida. Violência Simbólica reproduzida na escola à luz do pensamento de Freire, Bourdieu e Foucault. X Congresso Nacional de Educação - EDUCERE, PUC Paraná, Curitiba 7 a 10 de novembro de 2011. Disponível em: $<$ https://educere.bruc. com.br/arquivo/pdf2011/4984_2436.pdf>. Acesso em: 30 nov. 2020.

Recebido em: 28 de fevereiro de 2021.

Publicado em: 20 de abril de 2021. 